\title{
Effect of pre-exercise ingestion of $\alpha$-lactalbumin on subsequent endurance exercise performance and mood states
}

\author{
Lu Qin ${ }^{1,2}$, Feng-Hua Sun ${ }^{3 *}$, Yu Huang ${ }^{4}$, Sinead Sheridan ${ }^{5}$, Cindy Hui-Ping Sit $^{1}$ and \\ Stephen Heung-Sang Wong ${ }^{1}$ \\ ${ }^{1}$ Department of Sports Science and Physical Education, The Chinese University of Hong Kong, Shatin, Hong Kong, O0852 \\ ${ }^{2}$ Department of Anesthesiology, University of Nebraska Medical Center, Omaha, NE 68198, USA \\ ${ }^{3}$ Department of Health and Physical Education, The Education University of Hong Kong, Tai Po, Hong Kong, O0852 \\ ${ }^{4}$ Institute of Vascular Medicine, School of Biomedical Sciences and Li Ka Shing Institute of Health Sciences, The Chinese \\ University of Hong Kong, Shatin, Hong Kong, 00852 \\ ${ }^{5}$ Li Ka Shing Faculty of Medicine, School of Public Health, The University of Hong Kong, Pokfulam, Hong Kong, O0852 \\ (Submitted 23 April 2018 - Final revision received 29 August 2018 - Accepted 29 August 2018)
}

\begin{abstract}
This study investigated the effect of pre-exercise $\alpha$-lactalbumin ingestion on subsequent endurance exercise performance, muscle pain and mood states. In a two-stage cross-over counterbalance design, eleven male endurance runners (age: 31 (sE 2) years, height: 169.5 (sE 4.4) cm, weight: 63.6 (SE 5.1) kg, $\dot{\mathrm{VO}}$ 2max $_{\text {ma }} 58.8$ (se 6.3) $\mathrm{ml} / \mathrm{kg}$ per min) consumed two solutions (carbohydrate + $\alpha$-lactalbumin, CA; carbohydrate + whey protein isolate, $\mathrm{CW}) 2 \mathrm{~h}$ before a self-paced $21-\mathrm{km}$ run. Creatine kinase, IL-6, muscle pain, pressure pain threshold (PPT) and mood states were assessed $2 \mathrm{~h}$ before exercise, immediately before exercise (Pre-ex0) and immediately after exercise (Post-ex0). No difference was found in $21-\mathrm{km}$ running performance between two trials (CA $v$. CW: 115.85 (SE 5.20) $v$. 118.85 (se 5.51) min, $P=0 \cdot 48$ ). Compared with CW, CA led to

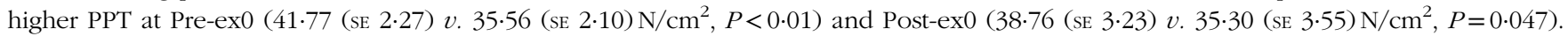
Compared with CW, CA reduced the feeling of fatigue at Post-ex0 $(P<0 \cdot 01)$; CA also reduced salivary cortisol levels at Post-ex0 $(0 \cdot 72$ (se $0 \cdot 07)$ v. $0.83(\mathrm{se} 0.13) \mathrm{ng} / \mathrm{ml}, P<0.01)$. In conclusion, the ingestion of $\alpha$-lactalbumin did not improve the $21-\mathrm{km}$ time-trial performance. However, compared with the pre-exercise ingestion of whey protein, that of $\alpha$-lactalbumin led to superior results during similar levels of endurance exercise: it elevated PPT and reduced the feeling of fatigue and the cortisol levels.
\end{abstract}

Key words: Half-marathons: Stress: Pain: Time trials

Long-distance endurance exercise (e.g. half-marathon and fulldistance marathon) demands high levels of energy, and carbohydrate $(\mathrm{CHO})$ is one of the chief energy sources drawn upon during exercise. The beneficial effect of pre-exercise $\mathrm{CHO}$ ingestion on endurance exercise performance is well established ${ }^{(1,2)}$. In addition, the co-ingestion of protein (PRO) and $\mathrm{CHO}$ has been extensively investigated in relation to postexercise recovery period ${ }^{(3-5)}$. To date, relatively little research has been conducted on the performance efficacy of the co-ingestion of PRO and $\mathrm{CHO}$ before exercise. In theory, the combined ingestion of $\mathrm{CHO}$ and $\mathrm{PRO}$ increases insulin levels more effectively than the ingestion of $\mathrm{CHO}$ alone, which may also enhance glucose disposal ${ }^{(6)}$. Therefore, it may be beneficial for sparing glycogen and suppressing the fat oxidation during the early phase of exercise ${ }^{(7,8)}$. Studies ${ }^{(9-12)}$ have reported inconsistent findings; however, a recent meta-analysis revealed that the addition of $\mathrm{PRO}$ in $\mathrm{CHO}$ solution improved exercise performance by $10.5 \%$ when compared with the original $\mathrm{CHO}$ solutions. The findings also suggested a $3.4 \%$ improvement in performance when PRO replaced a portion of $\mathrm{CHO}$, whereas energy was matched between two trials ${ }^{(13)}$. It should be noted that the included studies in this meta-analysis have a high heterogeneity in study protocol, participants and nutritional strategy. Therefore, the results should be explained cautiously. However, it seems that co-ingestion of $\mathrm{CHO}$ and PRO may benefit the exercise performance when being consumed before endurance exercise.

$\alpha$-Lactalbumin is a PRO derived from whey PRO. Compared with whey PRO, $\alpha$-lactalbumin is rich in tryptophan, which is the only precursor of serotonin. Serotonin is a neurotransmitter in the central nervous system (CNS) with the biological function in the regulation of some essential life behaviour. Serotonin

Abbreviations: AD, abdominal discomfort; BG, blood glucose; BW, body weight; CA, carbohydrate $+\alpha$-lactalbumin; CHO, carbohydrate; CK, creatine kinase; $\mathrm{CW}$, carbohydrate + whey protein isolated; LA, lactic acid; Post-ex0, immediately after exercise; PPT, pressure pain threshold; Pre-ex0, immediately before exercise; Pre-ex $2 \mathrm{~h}, 2 \mathrm{~h}$ before exercise; PRO, protein; TT, time trial.

* Corresponding author: F.-H. Sun, email fhsun@eduhk.hk 
synthesis enhancement in the dorsal horn of the spinal cord and the hypothalamus is essentially a response for reducing pain ${ }^{(14)}$. In most of the situations, physical exercise is not only terminated by energy substrate exhaustion but also by muscle exertion, especially muscle pain, which is a progressive discomfort relating to the inability to overcome the outflow of sensory information ${ }^{(15)}$. A previous study ${ }^{(16)}$ reported that, compared with placebo control, tryptophan supplementation before exercise improved peak power output, as well as distance covered in the last $20 \mathrm{~min}$ of a self-selected speed time-trial (TT) test. $\alpha$-Lactalbumin not only provides a more comprehensive amino acid profile compared with ingestion of pure tryptophan, but also prevents the possible side effects of pure tryptophan ingestion ${ }^{(17,18)}$. Therefore, public attention regarding the use of $\alpha$-lactalbumin for endurance exercise should be increased.

In our previous study ${ }^{(19)}$, compared with a placebo, ingestion of $\alpha$-lactalbumin significantly resulted in lower muscle pain and greater affective enhancement at $90 \mathrm{~min}$ of prolonged running exercise at constant individual intensity $\left(70 \% \dot{\mathrm{VO}}_{2 \max }\right)$. In another study ${ }^{(20)}$, participants ingested $\alpha$-lactalbumin and whey PRO within $2 \mathrm{~h}$ after $90 \mathrm{~min}$ of running. Compared with the results after ingestion of whey $\mathrm{PRO}$, an elevation of pressure pain threshold (PPT) occurred at $2 \mathrm{~h}$ after the ingestion of $\alpha$-lactalbumin. This change was associated with a relatively rapid recovery of fatigue. Thus far, few studies have investigated the effect of $\alpha$-lactalbumin ingestion before exercise with regard to individuals' TT performance, muscle damage and mood states. Therefore, this study was conducted to address the related research questions. The absorption of PRO can occur gradually through the gastrointestinal system, and the amino acids would appear in the blood stream in 15 min and peak at 75-120 min after ingestion. Accordingly, a hypothesis was established that ingestion of $\alpha$-lactalbumin $2 \mathrm{~h}$ before exercise improves subsequent exercise performance, compared with the ingestion of whey PRO.

\section{Methods}

\section{Ethics statement}

All procedures in this study were performed in accordance with the Declaration of Helsinki and were approved by the Ethics Committee of the Chinese University of Hong Kong. The procedures and potential risks of the study were fully explained to the participants. During the briefing session, the participants were allowed to freely raise questions related to the study. All participants signed the informed consent forms after the briefing session.

\section{Participants and experiment control}

A total of thirteen participants were recruited initially. However, two participants dropped out during the trial period because of schedule conflicts. Finally, eleven healthy participants (age: 31 (SE 3) year, height: 169.5 (SE 4.4) cm, weight: 63.6 (SE 5.1) kg, $\dot{\mathrm{V}} \mathrm{O}_{2 \max }: 58 \cdot 8$ (se $6 \cdot 3$ ) $\mathrm{ml} / \mathrm{kg}$ per min) eventually completed four separate tests, namely $\dot{\mathrm{V}}_{2 \max }$ test, familiarisation test and two main trials separated by a wash-out period of 7-21 d. Participants were required to refrain from strenuous exercise, as well as caffeine and alcohol consumption, for $48 \mathrm{~h}$ before each day of participation in the experiment. In addition, participants observed an overnight fasting state of $10-12 \mathrm{~h}$ before the main trial days; in particular, after 20.00 hours on the day preceding a trial day, participants were only allowed to consume water.

\section{Experimental protocol}

Main trials and drinking protocol. For each main trial, one participant reported to the same experimental site between 07.00 and 07.30 hours. Approximately half an hour was arranged for the participants to change into their sports gear, and use the bathroom to empty their bladder and colon. The participants then returned to the lab and sat quietly for $2 \mathrm{~h}$. During the 2-h pre-exercise rest, the prescribed drinks (carbohydrate + $\alpha$-lactalbumin (CA), carbohydrate + whey protein isolated (CW)) for the two main trials were arranged in a double-blinded crossover design. In the double-blinded arrangement, the drinks were marked as drink 1 or 2 by a research assistant. A drink was then randomly selected during the first trial; the remaining drink was applied in the next trial. The two types of PRO powders were purchased from the same manufacturer (Davisco ${ }^{\circledR}$ ). CHO and $\mathrm{PRO}$ were served at 0.66 and $0.34 \mathrm{~g} / \mathrm{kg}$ per h, respectively. $\mathrm{CHO}$ was served as a $6.6 \%(\mathrm{w} / \mathrm{v})$ solution (Pocari ${ }^{\circledR}$; Otsuka Pharmaceutical Co. Ltd). PRO powder was dissolved in the CHO solution for each serving. The total amount of solution and PRO powder was divided equally and ingested every $30 \mathrm{~min}$ during the $2 \mathrm{~h}$ before exercise. For instance, a participant with a body weight (BW) of $75 \mathrm{~kg}$ would consume a total of $1500 \mathrm{ml}$ of $\mathrm{CHO}$ solution and $51 \mathrm{~g}$ of PRO powder before exercise. At every $30 \mathrm{~min}, 300 \mathrm{ml}$ of solution with $10 \cdot 2 \mathrm{~g}$ of PRO powder would be served. In the study, after ingesting all assigned drinks, each participant ran on a treadmill at a self-selected speed for $21 \mathrm{~km}$. While running, participants were blinded to the running speed, heart rate and elapsed time. They were required to run as fast as they could to complete the trial. Participants were also served pure water at $2.5 \mathrm{ml} / \mathrm{kg} \mathrm{BW}$ at intervals of 8 and $16 \mathrm{~km}$ while they were running. The collection of BW data (MC-780U; TANITA $^{\circledR}$ ) and capillary blood and saliva samples, as well as the evaluation of perceptual responses (abdominal discomfort (AD), thirst, muscle pain, perceived exertion, mood states and PPT), was conducted $2 \mathrm{~h}$ before exercise (Pre-ex $2 \mathrm{~h}$ ), immediately before exercise (Pre-ex0) and immediately after exercise (Post-ex0). Standardised meals (energy: $75 \cdot 4$ (sE 2.1) kJ/kg; $57 \%$ CHO, $15 \%$ PRO, $28 \%$ fat) were provided for the remainder of the main trial day. Other than the standardised food, only water consumption was allowed before the evaluation on the next day. In the morning after the experimental day (Post-ex24h), each participant returned to the lab for a single set of capillary blood sampling, muscle pain scale evaluation and PPT assessment.

\section{Blood and salivary cortisol measurement}

Participants submerged their hands in warm water for approximately $1 \mathrm{~min}$. After the hand was dried with a clean 
swab, the sampling fingertip was sterilised and a capillary blood sample was withdrawn. For each sampling, $1 \mathrm{ml}$ of capillary blood was obtained using two $600-\mu \mathrm{l} \mathrm{K}^{+}$-EDTA anti-clotting multivettes (Multivettes ${ }^{\circledR}$ 600K3E; Sarstedt AG \& Co.). The blood samples were centrifuged (Primo ${ }^{\mathrm{TM}} \mathrm{R}$, Biofuge ${ }^{\circledR}$; Heraeus Ltd.) for $10 \mathrm{~min}$ at $3500 \mathrm{rpm}$ and $4^{\circ} \mathrm{C}$. Plasma samples were collected and deposited into Eppendorf tubes to avoid repeat freezing and thawing. The samples were then stored at $-80^{\circ} \mathrm{C}$ in an ultra-low-temperature freezer (Model MDFU52V, Sanyo ${ }^{\mathrm{TM}}$; Sanyo Electric Co. Ltd). Blood glucose (BG), lactic acid (LA), creatine kinase (CK), plasma IL-6, Hb and salivary cortisol were collected and measured using the methods described in our previous study ${ }^{(20)}$.

\section{Pressure pain threshold}

PPT was manually determined according to a previously described method $^{(21)}$. In brief, participants relaxed their legs in a supine resting position. A round metal probe was placed on the middle part of the rectus femoris. The force was increased by $3 \mathrm{~N} / \mathrm{cm}^{2}$ per $\mathrm{s}$ until the participant signalled that they felt a weak pain.

\section{Perception responses and mood states evaluation}

Muscle pain, $\mathrm{AD}$, thirst and perceived exertion were evaluated using rating scales that we applied in our previous studies ${ }^{(20,22)}$. Mood states were measured using the Chinese version of Brunel Mood Scale (BRUMS-C) ${ }^{(23)}$. Briefly, the BRUMS-C encompasses six dimensions: anger, confusion, fatigue, tension, depression and vigour. In the present study, the range of each mood dimension was determined according to the raw score of each dimension, as well as the total mood disturbance (TMD), calculated as the sum of the scores of negative dimensions (anger, confusion, tension, depression and fatigue) with the positive dimension (vigour) score substracted.

\section{Statistical analysis}

All continuous data were analysed using IBM SPSS (version 20.0) and presented as means with their standard errors. Crossover data for repeated measures were analysed using two-way repeated measures ANOVA. Treatment (CA, CW) and time (Preex2h, Pre-ex0, Post-ex0 and Post-ex24h) were considered within-subject factors, and trial order (the sequence in which the participant received the treatments) was considered a between-subject factor. Simple effect analysis with a Bonferroni post hoc test was applied to determine the difference among treatment or time. The sample size was calculated and validated using G*Power (version 3.1.9). The type of study design was chosen as $F$ test ANOVA repeat measures, within factors. The intraclass correlation was 0.80 between repeat measures. The effect size was estimated as 0.25 based on previous studies ${ }^{(24-26)}$ with similar primary outcomes as those of the present study (in TT performance and mood states). The statistical power was determined as $80 \%$, and the two-sided significance level was $0 \cdot 05$. The minimum sample size for each trial was eight participants.

\section{Results}

\section{Exercise performance}

Completion time of the $21-\mathrm{km}$ run was slightly less in the CA trial than in the CW trial; however, no significant difference was observed between both trials (CA $v$. CW: 115.85 (SE 5.20) $v$. $118 \cdot 85$ (se 5.51) $\min , P=0 \cdot 48)$.

\section{Creatine kinase and IL-6}

A main effect of time was found with CK $\left(F_{9,27}=28 \cdot 62, P<0 \cdot 01\right)$ and IL-6 $\left(F_{9,27}=27 \cdot 446, P<0 \cdot 01\right)$. Compared with Pre-ex $2 \mathrm{~h}, \mathrm{CK}$ levels increased at Post-ex24h following both CA (9.37 (sE 1.40) $v$. 3.86 (sE 0.84) $\mu \mathrm{kat} / 1, P<0.01$ ) and $\mathrm{CW}$ (8.21 (sE 0.93) v. 3.53 (se 0.46$) \mu \mathrm{kat} / \mathrm{l}, P<0 \cdot 01$ ). Compared with Pre-ex2h, IL-6 was higher at Post-ex0 in both CA (11.80 (sE 2.12) v. 2.49 (sE 0.74), $P<0.01$ ) and $\mathrm{CW}(12.33$ (se 2.64) v. 2.14 (SE 0.72), $P<0.01$ ) treatments. No treatment effect or treatment $\times$ time interaction effect $\left(F_{3,27}=0.688, P=0.567\right)$ was observed for CK (treatment: $F_{1,9}=0.568, P=0.470$; treatment $\times$ time: $\left.F_{3,27}=0.688, P=0.567\right)$ or IL-6 (treatment: $F_{1,9}=0.339, \quad P=0.575$; treatment $\times$ time: $F_{3,27}=0 \cdot 855, P=0 \cdot 476$ ) (Fig. 1).

\section{Salivary cortisol}

A main effect of time $\left(F_{2,18}=25 \cdot 88, P<0.01\right)$ and an interaction effect of treatment $\times$ time $\left(F_{3,27}=5 \cdot 29, P=0 \cdot 016\right)$ were found on

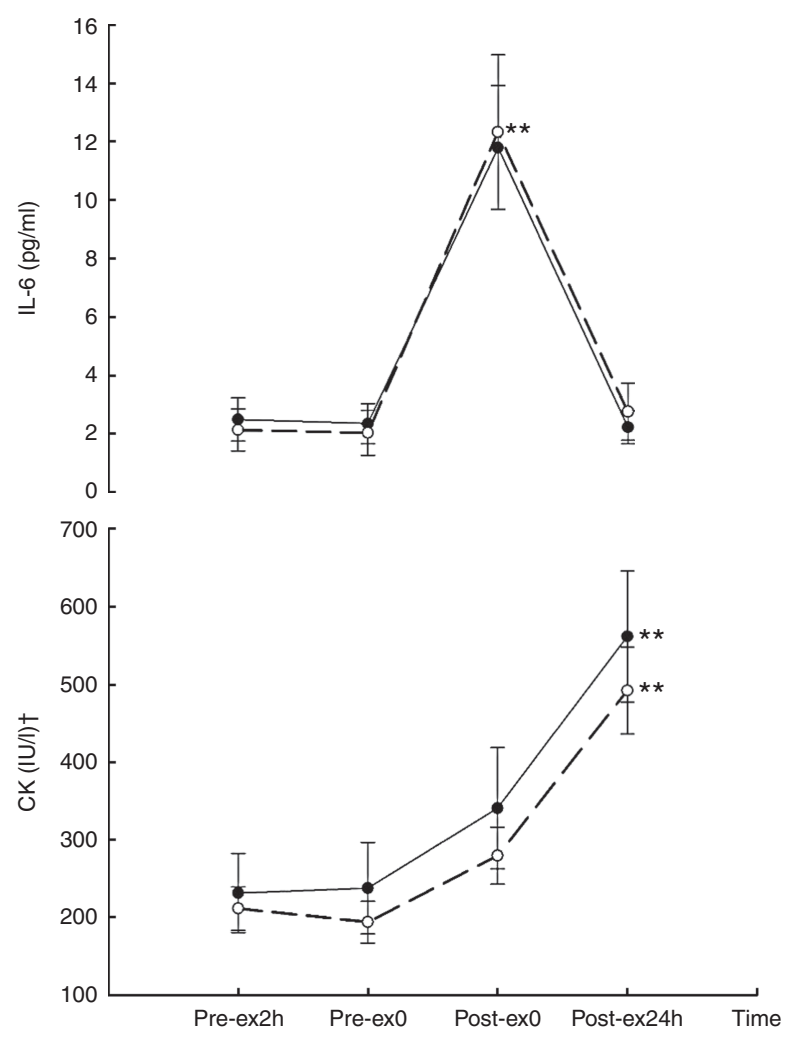

Fig. 1. Creatine kinase (CK) and IL-6 concentration in two main trials. ** $v$. $2 \mathrm{~h}$ before exercise (Pre-ex2h, $P<0.01$ ). carbohydrate $+a$-lactalbumin; $O$, carbohydrate + whey protein; Pre-ex0, immediately before exercise; Post-ex0, immediately after exercise; Post-ex24h, after the experimental day. † To convert CK in IU to $\mu$ kat, multiply by 0.0167 . 
(a)

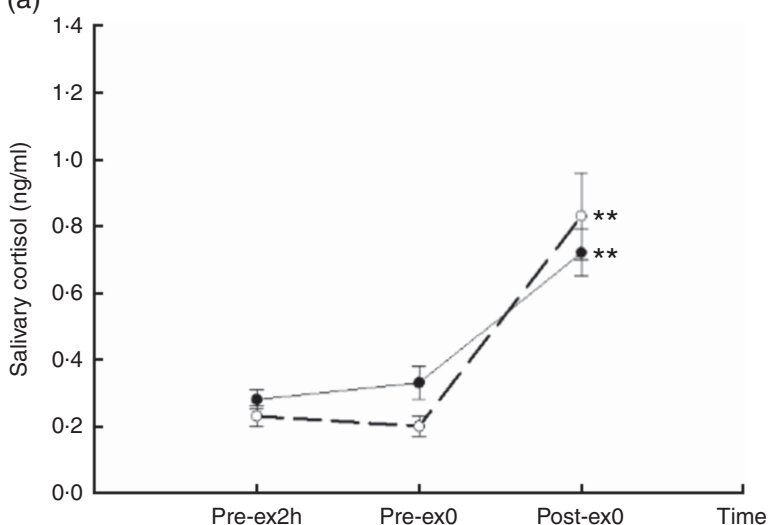

(b)

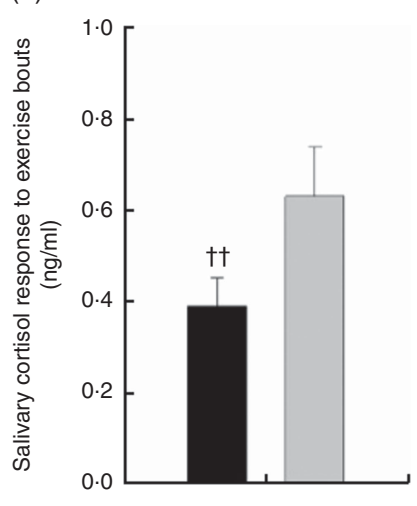

Fig. 2. Salivary cortisol responses in two main trials; (a) salivary cortisol concentration in different time points; (b) the change of salivary cortisol following exercise bouts (immediately after exercise (Post-ex0) minus immediately before exercise (Pre-ex0)). (a) ** $v$. $2 \mathrm{~h}$ before exercise (Pre-ex2h) and Pre-ex0 ( $P<0.01)$. CA $(O)$, Carbohydrate + $a$-lactalbumin; CW $(\bigcirc)$, carbohydrate + whey protein isolated. (b) $\dagger \dagger v$. $\mathrm{CW}(\square, P<0.01)$. $\square, \mathrm{CA}$.

salivary cortisol. No difference was observed between the basal reference values at Pre-ex $2 \mathrm{~h}(P=0 \cdot 174)$; however, there was a marginal difference in Pre-ex0 $(P=0.068)$. Compared with Pre-ex $2 \mathrm{~h}$ and Pre-ex0, the salivary cortisol was higher at Post-ex0 in CW and CA (all $P<0 \cdot 01$ ) (Fig. 2 (a)). To eliminate the potential difference in Pre-ex0 and, more importantly, to compare the cortisol response following two exercise trials, we compared the change of cortisol by subtracting the values in Post-ex0 with that in Pre-ex0. Compared with $\mathrm{CW}$, the change of salivary cortisol in Post-ex0 was lower in CA (0.39 (sE 0.06) v. 0.63 (sE 0.11$) \mathrm{ng} / \mathrm{ml}, P<0.01$ ) (Fig. 2(b)).

\section{Blood glucose and lactic acid}

A main effect of time was observed for both BG $\left(F_{2,18}=8.981\right.$, $P<0.01)$ and LA $\left(F_{2,18}=12.49, P<0.01\right)$. Compared with that at Pre-ex2h, BG was lower at Post-ex0 for both CA (4.28

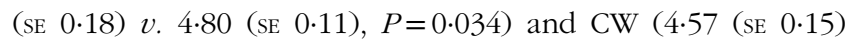
v. 4.66 (se 0.12), $P=0.037$ ). Compared with that at Pre-ex $2 \mathrm{~h}, \mathrm{LA}$ was higher at Post-ex0 in both of CA $(3.57$ (SE 0.78) $v .1 .14$ (SE 0.16 ) $\mathrm{mmol} / \mathrm{l}, P=0.014$ ) and $\mathrm{CW}(3.54$ (SE 0.77) $v$. 0.99 (sE $0 \cdot 10) \mathrm{mmol} / \mathrm{l}, P=0 \cdot 014$ ). Neither main effect of treatment nor interaction effect of treatment $\times$ time was observed for BG (treatment effect: $F_{1,9}=0.011, \quad P=0.092 ; \quad$ treatment $\times$ time: $\left.F_{2,18}=2 \cdot 562, P=0 \cdot 105\right)$ and LA (treatment effect: $F_{1,9}=1 \cdot 577$, $P=0 \cdot 241$; treatment $\times$ time: $\left.F_{2,18}=0 \cdot 176, P=0 \cdot 840\right)$ (Fig. 3).

\section{Body weight and $\mathrm{Hb}$}

A main effect of time was found on both BW $\left(F_{2,18}=172.56\right.$, $P<0.01)$ and $\mathrm{Hb}\left(F_{2,18}=6.76, P<0.01\right)$. Compared with that at Pre-ex $2 \mathrm{~h}, \mathrm{BW}$ was lower at Post-ex0 in both trials of CA $(P<0.01)$ and $\mathrm{CW}(P<0.01)$ treatments. Compared with that at Pre-ex $2 \mathrm{~h}, \mathrm{Hb}$ concentration was higher in $\mathrm{CA}(P<0 \cdot 01)$ and $\mathrm{CW}$ $(P<0 \cdot 01)$. Neither main effect of treatment nor interaction effect of treatment $\times$ time was observed for BW (treatment effect: $F_{1,9}=1.623, P=0.235$; treatment $\times$ time: $\left.F_{2,18}=1.409, P=0.135\right)$ and $\mathrm{Hb}$ (treatment effect: $F_{1,9}=0.126, P=0.731$; treatment $\times$ time: $F_{2,18}=1 \cdot 657, P=0 \cdot 219$ ) (Table 1 ).
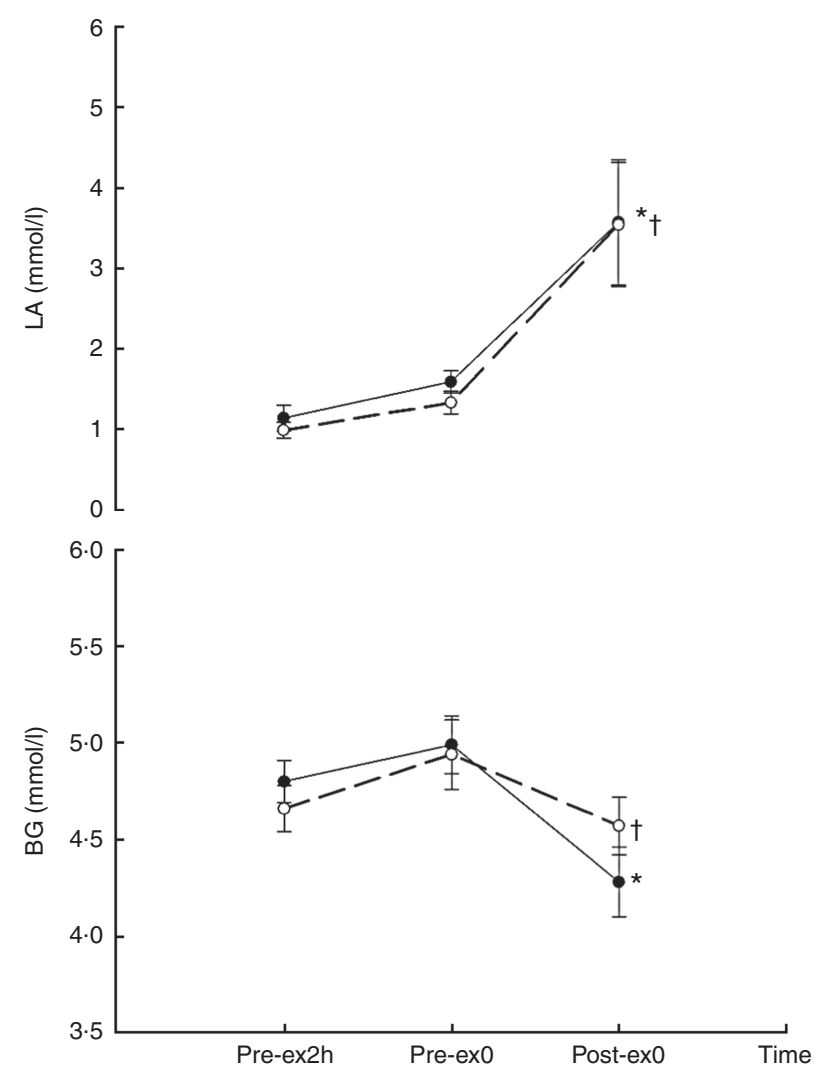

Fig. 3. Blood glucose (BG) and lactic acid (LA) concentration in two main trials. * $v$. $2 \mathrm{~h}$ before exercise (Pre-ex2h, $P=0.034)$. $\dagger v$. Pre-ex2h $(P=0.037)$. Carbohydrate $+a$-lactalbumin; $\bigcirc$, carbohydrate + whey protein; Pre-ex0, immediately before exercise; Post-ex0, immediately after exercise.

\section{Pressure pain threshold}

A main effect of treatment $\left(F_{1,9}=13.92, P<0.01\right)$ and interaction effect of treatment $\times$ time was observed for PPT $\left(F_{3,27}=6 \cdot 604, P<0 \cdot 01\right)$. Compared with that for $\mathrm{CW}$ treatment, $\mathrm{PPT}$ was higher at Pre-ex0 (41.77 (SE 2.27) $v . \quad 35.56$ $($ se $\left.2 \cdot 10) \mathrm{N} / \mathrm{cm}^{2}, P<0.01\right)$ and Post-ex0 (38.76 (se 3.23) v. 35.30 $(\operatorname{se} 3.55) \mathrm{N} / \mathrm{cm}^{2}, P=0.047$ ) in CA (Fig. 4). 
Table 1. Body weight (BW) and $\mathrm{Hb}$ concentration in both trials (Mean values with their standard errors)

\begin{tabular}{|c|c|c|c|c|c|c|}
\hline & \multicolumn{2}{|c|}{ Pre-ex2h } & \multicolumn{2}{|c|}{ Pre-ex0 } & \multicolumn{2}{|c|}{ Post-ex0 } \\
\hline & Mean & SE & Mean & SE & Mean & SE \\
\hline \multicolumn{7}{|c|}{ BW (kg) } \\
\hline $\mathrm{CA}$ & 64.5 & 1.6 & 64.6 & 1.6 & $62 \cdot 9^{\star *}$ & 1.6 \\
\hline CW & $64 \cdot 2$ & 1.7 & 64.3 & 1.7 & $62 \cdot 7^{\star *}$ & 1.7 \\
\hline \multicolumn{7}{|c|}{$\mathrm{Hb}(\mathrm{g} / \mathrm{l})$} \\
\hline CA & 14.21 & 0.34 & 14.71 & 0.44 & $15 \cdot 64^{\star *}$ & 0.29 \\
\hline CW & 14.83 & 0.29 & 14.80 & 0.48 & $15 \cdot 13$ & 0.37 \\
\hline
\end{tabular}

Pre-ex $2 \mathrm{~h}, 2 \mathrm{~h}$ before exercise; Pre-ex0, immediately before exercise; Post-ex0, immediately after exercise; $\mathrm{CA}$, carbohydrate + $a$-lactalbumin; $\mathrm{CW}$, carbohydrate + whey protein. ** v. Pre-ex2h $(P<0.01)$.

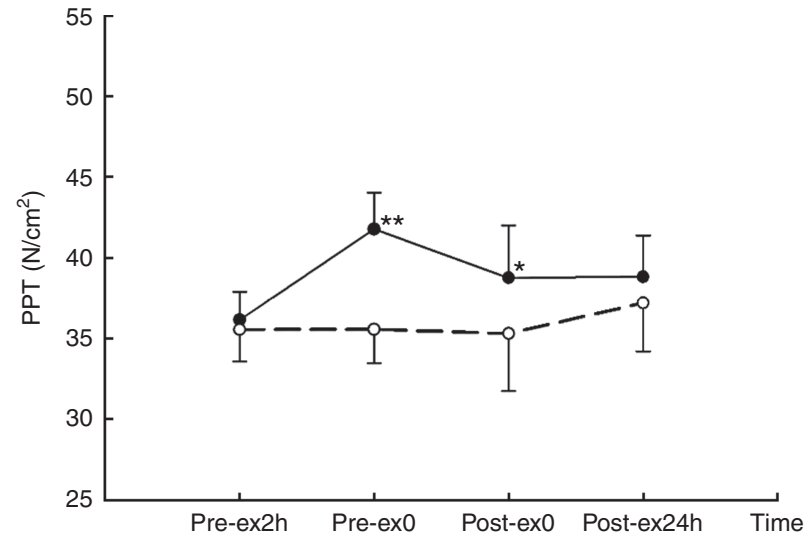

Fig. 4. Pressure pain threshold (PPT) in two main trials. * $v$. carbohydrate + whey protein isolated (CW (O), $P=0.047)$. ${ }^{\star \star}$ v. CW $(P<0.01)$. Carbohydrate $+a$-lactalbumin; Pre-ex $2 \mathrm{~h}, 2 \mathrm{~h}$ before exercise; Pre-ex0, immediately before exercise; Post-ex0, immediately after exercise; Post-ex24h, after the experimental day.

Table 2. Muscle pain, abdominal discomfort $(A D)$ and thirst in both trials (Mean values with their standard errors)

\begin{tabular}{|c|c|c|c|c|c|c|c|c|}
\hline & \multicolumn{2}{|c|}{ Pre-ex2h } & \multicolumn{2}{|c|}{ Pre-ex0 } & \multicolumn{2}{|c|}{ Post-ex0 } & \multicolumn{2}{|c|}{ Post-ex24h } \\
\hline & Mean & SE & Mean & SE & Mean & SE & Mean & SE \\
\hline \multicolumn{9}{|c|}{ Muscle pain } \\
\hline $\mathrm{CA}$ & 0.54 & 0.23 & 0.51 & 0.23 & $4 \cdot 04^{\star *}$ & 0.79 & 1.50 & 0.38 \\
\hline $\mathrm{CW}$ & 0.72 & 0.30 & 1.04 & 0.47 & $3.63^{\star \star}$ & 0.66 & 1.45 & 0.35 \\
\hline \multicolumn{9}{|l|}{$A D$} \\
\hline $\mathrm{CA}$ & 1.63 & 0.47 & 1.00 & 0.30 & $3 \cdot 27^{\star *}$ & 0.85 & - & \\
\hline $\mathrm{CW}$ & 1.45 & 0.56 & 1.36 & 0.43 & $2 \cdot 36^{\star \star}$ & 0.64 & - & \\
\hline \multicolumn{9}{|l|}{ Thirst } \\
\hline $\mathrm{CA}$ & 1.36 & 0.45 & 0.54 & 0.20 & $4 \cdot 36^{\star \star}$ & 0.66 & - & \\
\hline CW & $2 \cdot 36$ & 0.72 & $1 \cdot 36$ & 0.54 & $4.00^{\star \star}$ & 0.60 & - & \\
\hline
\end{tabular}

Pre-ex2h, $2 \mathrm{~h}$ before exercise; Pre-ex0, immediately before exercise; Post-ex0, immediately after exercise; Post-ex24h, after the experimental day; CA, carbohydrate $+a$-lactalbumin; $C W$, carbohydrate + whey protein; pain, rating of muscle pain

$A D$, rating of abdominal discomfort; thirst, rating of thirst.

** $v$. Pre-ex2h $(P<0.01)$.

\section{Muscle pain, abdominal discomfort and thirst}

Main effects of time were observed for muscle pain $\left(F_{3,27}=21 \cdot 16, P<0 \cdot 01\right), \mathrm{AD}\left(F_{2,18}=5.493, P=0.014\right)$ and thirst $\left(F_{2,18}=24 \cdot 677, P<0 \cdot 01\right)$. Compared with that at Pre-ex2h, rating of muscle pain was higher at Post-ex0 $(P<0 \cdot 01)$ in both trials.
Table 3. Mood states in both trials (Mean values with their standard errors)

\begin{tabular}{|c|c|c|c|c|c|c|}
\hline & \multicolumn{2}{|c|}{ Pre-ex2h } & \multicolumn{2}{|c|}{ Pre-ex0 } & \multicolumn{2}{|c|}{ Post-ex0 } \\
\hline & Mean & SE & Mean & $\mathrm{SE}$ & Mean & SE \\
\hline \multicolumn{7}{|l|}{ Anger } \\
\hline CA & 0.45 & 0.36 & 0.09 & 0.09 & 0.63 & 0.63 \\
\hline CW & 0.27 & 0.19 & 0.09 & 0.09 & 0.72 & 0.44 \\
\hline \multicolumn{7}{|c|}{ Confusion } \\
\hline CA & $2 \cdot 18$ & 0.84 & $0.63^{*}$ & 0.38 & $1 \cdot 18$ & 0.82 \\
\hline CW & 1.72 & 0.66 & 2.00 & 0.74 & 1.45 & 0.79 \\
\hline \multicolumn{7}{|c|}{ Depression } \\
\hline $\mathrm{CA}$ & 0.72 & 0.38 & 0.09 & 0.09 & 0.63 & 0.63 \\
\hline CW & 0.63 & 0.27 & 0.27 & 0.19 & 0.72 & 0.72 \\
\hline \multicolumn{7}{|l|}{ Fatigue } \\
\hline $\mathrm{CA}$ & 3.54 & 0.56 & 2.72 & 0.42 & $5 \cdot 27^{\star \star}, \dagger$ & $1 \cdot 16$ \\
\hline CW & 2.82 & 0.73 & 2.63 & 0.72 & $5 \cdot 82$ & 0.84 \\
\hline \multicolumn{7}{|c|}{ Tension } \\
\hline $\mathrm{CA}$ & 1.09 & 0.72 & 0.18 & 0.18 & $1 \cdot 18$ & 0.90 \\
\hline CW & 1.36 & 0.53 & 0.90 & 0.39 & 0.90 & 0.63 \\
\hline \multicolumn{7}{|l|}{ Vigour } \\
\hline $\mathrm{CA}$ & 3.00 & 0.42 & 3.00 & 0.58 & 3.09 & 0.53 \\
\hline CW & 4.09 & 0.69 & 3.72 & 0.72 & $4 \cdot 18$ & 0.85 \\
\hline \multicolumn{7}{|l|}{ TMD } \\
\hline $\mathrm{CA}$ & $6 \cdot 81$ & $2 \cdot 67$ & 1.45 & 0.97 & $5 \cdot 72$ & 3.66 \\
\hline CW & $4 \cdot 27$ & 1.49 & 3.09 & 1.52 & 5.00 & $3 \cdot 13$ \\
\hline
\end{tabular}

Pre-ex2h, $2 \mathrm{~h}$ before exercise; Pre-ex0, immediately before exercise; Post-ex0, immediately after exercise; $\mathrm{CA}, \mathrm{CHO}+a$-lactalbumin; $\mathrm{CW}=\mathrm{CHO}+$ Whey $\mathrm{PRO}$; TMD, total mood disturbance.

* v. CW $(P=0.039)$

** v. CW $(P<0.01)$

† v. Pre-ex0 $(P=0.044)$.

Compared with that at Pre-ex0, AD and thirst were higher at Post-ex0 $(P<0 \cdot 01)$. Neither a main effect of treatment nor interaction effect of treatment $x$ time was found on muscle pain (treatment effect: $F_{1,9}=0.15, \quad P=0.707$; treatment $\times$ time: $F_{3,27}=1 \cdot 486, \quad P=0 \cdot 241$ ), AD (treatment effect: $F_{1,9}=1 \cdot 196$, $P=0.303$; treatment $\times$ time: $\left.F_{2,18}=2.585, P=0.103\right)$ or thirst (treatment effect: $F_{1,9}=0.980, \quad P=0.348 ; \quad$ treatment $\times$ time: $F_{2,18}=2 \cdot 511, P=0 \cdot 109$ ) (Table 2).

\section{Mood states}

An interaction effect of treatment and time was observed for the feeling of fatigue $\left(F_{2,18}=7 \cdot 327, P<0 \cdot 01\right)$. Compared with that in $\mathrm{CW}$ trial, feeling of fatigue was lower at Post-ex0 in CA trial $(P<0.01)$. An interaction effect of treatment and time was observed for the feeling of confusion $\left(F_{2,18}=3.743, P=0.044\right)$. Compared with $\mathrm{CW}$, feeling of confusion was lower in $\mathrm{CA}$ at Pre-ex2h $(P=0.039)$. A marginal main effect of time was observed for the feeling of fatigue (time: $F_{2,18}=3.405$, $P=0.056)$. Additional multivariate test revealed that the time effect was marginal in the $\mathrm{CW}$ trial $(P=0.073)$. Compared with Pre-ex0, there was a trend in increasing feeling of fatigue at Post-ex0 in CW $(P=0.095)$. No main effect of time was identified on feelings of anger (time: $F_{2,18}=1.968, P=0 \cdot 169$ ), confusion $\left(F_{2,18}=0.771, \quad P=0.477\right)$, depression $\left(F_{2,18}=1.312\right.$, $P=0.294)$, tension $\left(F_{2,18}=1.587, \quad P=0.232\right)$, vigour $\left(F_{2,18}=0 \cdot 213, P=0 \cdot 810\right)$ and $\operatorname{TMD}\left(F_{2,18}=1.586, P=0.232\right)$. A marginal treatment effect was observed for the feeling of confusion $\left(F_{1,9}=4 \cdot 11, P=0.073\right)$. No main effect of treatment 
was observed for the feeling of anger $\left(F_{1,9}=0.371, P=0.558\right)$, depression $\quad\left(F_{1,9}=0.096, \quad P=0.763\right), \quad$ fatigue $\left(F_{1,9}=0.254\right.$, $P=0.627)$, tension $\left(F_{1,9}=0.103, P=0.755\right)$, vigour $\left(F_{1,9}=1.768\right.$, $P=0.216)$ and TMD $\left(F_{1,9}=2 \cdot 222, P=0 \cdot 170\right)$ (Table 3$)$.

\section{Discussion}

The main findings of this study are summarised as follows: (1) A 21-km run following CA and CW ingestion increased CK and IL-6 levels; (2) no significant difference was observed between the 21-km TT performance for CA and CW treatments; (3) compared with that in CW, PPT was higher at Pre-ex0 and Post-ex0 in the CA trial; (4) compared with that in $\mathrm{CW}$, the change of cortisol concentration was lower following the exercise bout in the CA trial; and (5) compared with that in the $\mathrm{CW}$ trial, feeling of fatigue was lower at Post-ex0 in the CA trial.

Time to exhaustion (TTE) and TT are widely applied in evaluations of endurance exercise performance ${ }^{(27)}$. TTE is measured at a pre-determined exercise intensity, speed or power output. TT is evaluated by either the time to complete a pre-determined distance or the amount of work or distance completed within a predetermined time. Compared with that of TTE, the CV of TT is lower. In addition, TT is more relevant to situations of real-world competition. In two of our previous studies, an exercise protocol of $90 \mathrm{~min}$ running was used. This time duration is closer to the time required for trained runners to run $21 \mathrm{~km}$. Therefore, a $21-\mathrm{km}$ TT test was adopted in the present study to mimic a half-marathon race. The results suggested that CA and CW had similar effects on $21-\mathrm{km}$ TT performance, contradicting our initial hypothesis that ingestion of $\alpha$-lactalbumin enhances exercise performance. However, this initial hypothesis was based on the potential beneficial effect of $\alpha$-lactalbumin to attenuate the muscle pain and enhance the mood states. The optimal mood for exercise performance can vary by individual and should be considered ${ }^{(28)}$, and it is also possible that this potential benefit may be more significant in more strenuous exercise such as full-distance marathon running.

PRO ingestion before exercise provides an abundant pool of amino acids during the exercise. Because amino acids, particularly the branched-chain amino acids, in whey PRO are important for energy substrate metabolism and muscle PRO synthesis, the increased availability of amino acids in the bloodstream may improve the substrate utilisation and attenuate muscle damage following exercise. Studies have demonstrated that improvements in exercise performance are associated with a reduction in the biomarkers of muscle damage (e.g. CK) and muscle pain/soreness ${ }^{(9,10,29)}$. This suggested that the enhancement of exercise performance following the PRO ingestion was partly due to the reduction of muscle damage and muscle pain. In the present study, prescribed treatments (CA and $\mathrm{CW}$ ) were served $2 \mathrm{~h}$ before the exercise. The amounts of $\mathrm{CHO}$ and $\mathrm{PRO}$ were identical; only the types of PRO differed between the two treatments. Similar BG responses (Fig. 3) suggested similar $\mathrm{CHO}$ availability in both trials. No difference between $\mathrm{CA}$ and $\mathrm{CW}$ trials was identified with regard to CK or IL-6 (Fig. 1). This result suggested that CA and CW exhibited similar effects on muscle damage when ingested before exercise.

Strenuous prolonged exercise induces an increase in metabolic and mechanical stress on the peripheral muscle. Increased production of ATP results in the activation the P2X purinoceptors, which subsequently enhances the excitability of the sensory neurons. In addition, both increasing metabolism and the muscle ischaemia induced by mechanical stress induces increasing metabolite concentration of LA, which can result in the elevation of the $\mathrm{Na}^{+}$channel current in sensory responses. Moreover, the receptors of the transient receptor potential vanilloid type 1 and acid-sensing ion channel can be also upregulated in sensory neurons ${ }^{(30)}$. All those aforementioned responses cause the excitation of nociceptive afferents and predisposition to accelerating muscle pain. Thus, in the present study, the rating score of muscle pain increased following exercise in both trials (Table 2). In both situations before exercise (Pre-ex2h, Pre-ex0) and after exercise (Post-ex0), participants received no mechanical stimulus from exercise bout. The PPT assessment was applied as an external mechanical stimulation. At Pre-ex0 and Post-ex0, PPT was higher in the CA trial than that in the CW trial (Fig. 4). This indicated lower pain sensitivity after the ingestion of CA than after that of $\mathrm{CW}$. Compared with whey PRO, $\alpha$-lactalbumin possesses similar amounts of other large neutral amino acids (LNAA) in addition to high tryptophan content. The higher amount of tryptophan may enter either the muscle tissue or the CNS. The lower pain sensitivity may be attributed to the greater amount of amino acids available for muscle PRO synthesis. In this study, considering the mood states evaluation, invasive muscle biopsy was not conducted to avoid extra emotional stimulus. Histological characteristics and PRO expression levels in muscles therefore could not be observed. By contrast, total tryptophan:LNAA ratio in plasma may have increased following the ingestion of $\alpha$-lactalbumin. Serotonin synthesis in the hypothalamus is positively associated with total tryptophan concentration $^{(31)}$; thus, the serotonin availability in the CNS, including the hypothalamus, may have increased following CA ingestion. Increased serotonin availability in the hypothalamus reduces the transmission of pain ${ }^{(32)}$. The result presented herein is partly consistent with that of the aforementioned exercise performance study ${ }^{(16)}$.

Regarding the stress situation, cortisol is considered as an indicator of distressful affect. A previous study ${ }^{(33)}$ found that the ingestion of $\alpha$-lactalbumin induced the enhancement of mood states and reduced the cortisol responses in stress-vulnerable subjects following experimental inducement of stress by noise. In addition, we have previously demonstrated that the ingestion of $\alpha$-lactalbumin reduced cortisol and the feeling of the fatigue to a greater extent than did ingestion of $\mathrm{CW}$ during the 4-h postexercise recovery ${ }^{(20)}$. In the present study, cortisol concentration increased in both trials following exercise, and there was an interaction effect of treatment $\times$ time (Fig. 2(a)). The change of cortisol concentration was higher in CW than CA at the end of exercise (Fig. 2(b)), which is consistent with the cortisol responses in other stress stimulations. It should be noted that the cortisol level seemed to be higher in CA than CW following 2-h pre-exercise rest (Pre-ex0), which was unusual in the 
experiment because participants were neither directly under exercise stimulation nor the after-effects of the exercise. As mentioned above, $\alpha$-lactalbumin possesses higher tryptophan than whey, and therefore induces higher serotonin availability in CNS. In resting status without stimulation, increasing the amount of serotonin stimulates the production of corticotrophin-releasing factor in the hypothalamus, as well as adrenocorticotrophin in the anterior pituitary gland. The function of the hypothalamic-pituitary-adrenal (HPA) axis is therefore enhanced and induces the increased secretion of cortisol $^{(34,35)}$. However, this speculation has to be further investigated before drawing any conclusion. Under the stimulation of prolonged strenuous exercise, the function of HPA axis was thoroughly activated. The activation effect of serotonin on the HPA axis results in an increase in the negative feedback of cortisol to HPA, dampening the sympathetic stress responses. In addition, PPT was higher at Post-ex0 in CA than CW. The attenuation of increasing fatigue following exercise tended to be greater in CA than $\mathrm{CW}$, as reflected in a marginal time effect in the CW trial but not in the CA trial.

In summary, the pre-exercise ingestion of $\alpha$-lactalbumin did not improve the $21-\mathrm{km}$ TT performance. However, the pre-exercise ingestion of $\alpha$-lactalbumin was superior to the pre-exercise ingestion of whey PRO in elevating PPT, and corresponded with lower feeling of fatigue and cortisol response following similar endurance exercise of similar duration.

\section{Acknowledgements}

The authors show their grateful appreciation to the participants' diligent commitment in this study. Mr Chi Wai Lau offered his valued expertise in the laboratory practice.

This study was supported by Lee Hysan Foundation Research Grant Scheme and the supportive funding from the Department of Sports Science and Physical Education in the Chinese University of Hong Kong.

L. Q. and F.-H. S. were responsible for designing the study, conducting data analysis, interpreting the results, preparing for the submission and revising the manuscript. Y. H. offered his human physiology expertise and organised the biological sample evaluation. S. S. offered contributions in manuscript preparation and English proofreading. C. H.-P. S. provided her expertise in interpreting the experimental results of psychological measurements. S. H.-S. W. coordinated and supervised the study design, data analysis and manuscript preparation.

The authors declare that there are no conflicts of interest.

\section{References}

1. Correia-Oliveira CR, Bertuzzi R, Kiss MAPDM, et al. (2013) Strategies of dietary carbohydrate manipulation and their effects on performance in cycling time trials. Sports Med $\mathbf{4 3}$, 707-719.

2. Vandenbogaerde TJ \& Hopkins WG (2011) Effects of acute carbohydrate supplementation on endurance performance: a meta-analysis. Sports Med 41, 773-792.
3. Ivy JL, Goforth HW Jr, Damon BM, et al. (2002) Early postexercise muscle glycogen recovery is enhanced with a carbohydrate-protein supplement. J Appl Physiol 93, $1337-1344$.

4. van Loon LJ, Saris WH, Kruijshoop M, et al. (2000) Maximizing postexercise muscle glycogen synthesis: carbohydrate supplementation and the application of amino acid or protein hydrolysate mixtures. Am J Clin Nutr 72, 106-111.

5. Koopman R, Pannemans DL, Jeukendrup AE, et al. (2004) Combined ingestion of protein and carbohydrate improves protein balance during ultra-endurance exercise. Am J Physiol Endocrinol Metab 287, E712-E720.

6. Manders RJ, Wagenmakers AJ, Koopman R, et al. (2005) Coingestion of a protein hydrolysate and amino acid mixture with carbohydrate improves plasma glucose disposal in patients with type 2 diabetes. Am J Clin Nutr 82, 76-83.

7. Morifuji M, Kanda A, Koga J, et al. (2011) Preexercise ingestion of carbohydrate plus whey protein hydrolysates attenuates skeletal muscle glycogen depletion during exercise in rats. Nutrition 27, 833-837.

8. Coyle EF, Jeukendrup AE, Wagenmakers AJ, et al. (1997) Fatty acid oxidation is directly regulated by carbohydrate metabolism during exercise. Am J Physiol Endocrinol Metab 273, E268-E275.

9. Saunders MJ, Kane MD \& Todd MK (2004) Effects of a carbohydrate-protein beverage on cycling endurance and muscle damage. Med Sci Sports Exerc 36, 1233-1238.

10. Saunders MJ, Luden ND \& Herrick JE (2007) Consumption of an oral carbohydrate-protein gel improves cycling endurance and prevents postexercise muscle damage. J Strength Cond Res 21, 678-684.

11. Martínez-Lagunas V, Ding Z, Bernard JR, et al. (2010) Added protein maintains efficacy of a low-carbohydrate sports drink. J Strength Cond Res 24, 48-59.

12. Van Essen M \& Gibala MJ (2006) Failure of protein to improve time trial performance when added to a sports drink. Med Sci Sports Exerc 38, 1476-1483.

13. Stearns RL, Emmanuel H, Volek JS, et al. (2010) Effects of ingesting protein in combination with carbohydrate during exercise on endurance performance: a systematic review with meta-analysis. J Strength Cond Res 24, 2192-2202.

14. Jacobs BL, Martín-Cora FJ \& Fornal CA (2002) Activity of medullary serotonergic neurons in freely moving animals. Brain Res Rev 40, 45-52.

15. Noakes TD, Gibson ASC \& Lambert EV (2005) From catastrophe to complexity: a novel model of integrative central neural regulation of effort and fatigue during exercise in humans: summary and conclusions. Br J Sports Med 39, $120-124$

16. Javierre C, Segura R, Ventura JL, et al. (2010) L-Tryptophan supplementation can decrease fatigue perception during an aerobic exercise with supramaximal intercalated anaerobic bouts in young healthy men. Int J Neurosci 120, 319-327.

17. Kilbourne EM, Philen R, Kamb M, et al. (1996) Tryptophan produced by Showa Denko and epidemic eosinophiliamyalgia syndrome. J Rheumatol 46, 81-88; discussion 89-91.

18. Porter RJ, Gallagher P, Watson S, et al. (2003) Elevated prolactin responses to $\mathrm{L}$-tryptophan infusion in medication-free depressed patients. Psychopharmacology 169, 77-83.

19. Qin L, Wong SH, Sun FH, et al. (2017) The effect of carbohydrate and protein co-ingestion on energy substrate metabolism, sense of effort, and affective responses during prolonged strenuous endurance exercise. Physiol Behav 174, 170-177.

20. Qin L, Wong SH, Sun F-H, et al. (2017) Effects of alphalactalbumin or whey protein isolate on muscle damage, 
muscle pain, and mood states following prolonged strenuous endurance exercise. Front Physiol 8, 754.

21. Astokorki A \& Mauger AR (2017) Tolerance of exerciseinduced pain at a fixed rating of perceived exertion predicts time trial cycling performance. Scand J Med Sci Sports 27, 309-317.

22. Li L, Wong SHS \& Sun FH (2015) Effects of protein addition to carbohydrate-electrolyte solutions on postexercise rehydration. J Exerc Sci Fit 13, 8-15.

23. Zhang C-Q, Si G, Chung P-K, et al. (2014) Psychometric properties of the Brunel Mood Scale in Chinese adolescents and adults. J Sports Sci 32, 1465-1476.

24. Coull N, Chrismas B, Watson P, et al. (2016) Tyrosine ingestion and its effects on cognitive and physical performance in the heat. Med Sci Sports Exerc 48, 277-286.

25. Lane AM, Whyte GP, Shave R, et al. (2005) Mood disturbance during cycling performance at extreme conditions. J Sports Sci Med 4, 52-57.

26. Gui Z, Sun F, Si G, et al. (2017) Effect of protein and carbohydrate solutions on running performance and cognitive function in female recreational runners. PLOS ONE 12, e0185982.

27. Temesi J, Johnson NA, Raymond J, et al. (2011) Carbohydrate ingestion during endurance exercise improves performance in adults. $J$ Nutr 141, 890-897.
28. Lane AM \& Terry PC (2000) The nature of mood: development of a conceptual model with a focus on depression. J Appl Sport Psychol 12, 16-33.

29. Millard-Stafford M, Warren GL, Thomas LM, et al. (2005) Recovery from run training: efficacy of a carbohydrate-protein beverage? Int J Sport Nutr Exerc Metab 15, 610-624.

30. Li J \& Xing J (2012) Muscle afferent receptors engaged in augmented sympathetic responsiveness in peripheral artery disease. Front Physiol 3, 247.

31. Bloxam D, Tricklebank M, Patel A, et al. (1980) Effects of albumin, amino acids and clofibrate on the uptake of tryptophan by the rat brain. J Neurochem 34, 43-49.

32. Kupers R, Frokjaer VG, Erritzoe D, et al. (2011) Serotonin transporter binding in the hypothalamus correlates negatively with tonic heat pain ratings in healthy subjects: a [11C]DASB PET study. NeuroImage 54, 1336-1343.

33. Markus CR, Olivier B, Panhuysen GE, et al. (2000) The bovine protein $\alpha$-lactalbumin increases the plasma ratio of tryptophan to the other large neutral amino acids, and in vulnerable subjects raises brain serotonin activity, reduces cortisol concentration, and improves mood under stress. Am J Clin Nutr 71, 1536-1544.

34. Axelrod J \& Reisine TD (1984) Stress hormones - their interaction and regulation. Science 224, 452-459.

35. Dinan TG (1996) Serotonin and the regulation of hypothalamic-pituitary-adrenal axis function. Life Sci 58, 1683-1694. 